\title{
Tribological behavior comparisons of high chromium stainless and mild steels against high-speed steel and ceramics at high temperatures
}

\author{
Shaogang CUI ${ }^{1}$, Yangzhen LIU ${ }^{1, *}$, Tong WANG ${ }^{2}$, Kiet TIEU ${ }^{2}$, Long WANG ${ }^{2, *}$, Dahai ZENG ${ }^{1}$, Zhou LI $^{2}$, Wei LI ${ }^{1}$ \\ ${ }^{1}$ Institute of Advanced Wear \& Corrosion Resistant and Functional Materials, Jinan University, Guangzhou 510632, China \\ ${ }^{2}$ School of Mechanical, Materials, Mechatronic and Biomedical Engineering, University of Wollongong, NSW 2522, Australia \\ Received: 19 August 2020 / Revised: 19 December 2020 / Accepted: 19 March 2021 \\ (C) The author(s) 2021.
}

\begin{abstract}
High-temperature tribology, which is often involved during hot metal forming, is controlled via oxidation on a rubbing surface. However, for high chromium stainless steel (ST), where oxidation is strongly inhibited, the effect of counterface materials on tribological behavior is yet to be elucidated. In this study, the effects of counterfaces on the tribological behavior of 253MA ST and mild steel (MS) are investigated via a ball-on-disc test at $900{ }^{\circ} \mathrm{C}$ using a $20 \mathrm{~N}$ load. The results reveal that high-speed steel (HSS) experiences severe abrasive wear with $\mathrm{MS}$ and causes severe sticking problems with $\mathrm{ST}$. $\mathrm{Si}_{3} \mathrm{~N}_{4}$ and $\mathrm{SiC}$ present substantially stronger abrasive wear resistance than HSS with MS, and the friction coefficients are dependent on the type of ceramic. Both ceramics can facilitate the establishment of a thick tribo-oxide layer $(>3 \mu \mathrm{m})$ on ST to prevent sticking; however, this is accompanied by severe pull-out and fracture wear. The effects of the counterface on the mechanical properties of the tribo-oxide layer, near-surface transformation, and the responses of the tribo-oxide layer to friction and wear are discussed. This study contributes to the understanding of interfacial tribological behaviors when different types of tools are used on MS and ST.
\end{abstract}

Keywords: austenitic stainless steel (ST); counterface materials; high-temperature tribology; sticking problem; tribo-oxide layer

\section{Introduction}

The majority of tribological studies regarding metallic materials are restricted to room temperature. Only a few are conducted at high temperatures, and they typically involve industrial applications in internal combustion engines, power generation, aerospace, and hot metal forming operations such as hot rolling, hot stamping, high-speed machining, and hot drawing of tubes. Significant changes in morphology, microstructure, and mechanical properties, as well as heavy oxidation, and rapid diffusion at the tribosurface occur when materials are exposed to high stresses and temperatures; these factors and their interactions complicate high-temperature tribology.

Some studies have been conducted to understand the tribo-interface evolution at high temperatures. Blau [1] reported that the response of sliding interfaces at high temperatures is governed by at least three factors: the mechanical properties of the products formed on the sliding surface, the tendency of products to form stable tribo-layers, and the resistance of the bulk metals in the subsurface to deformation and fracture. The wear behavior during high-temperature sliding is primarily controlled by the contact conditions and the nature of the oxide layer formation. The transition from severe adhesive/abrasive to mild oxidative wear in high-temperature tribology can be

* Corresponding authors: Yangzhen LIU, E-mail: yangzhenliu@jnu.edu.cn; Long WANG, lw010@uowmail.edu.au 
achieved if a compact and smooth load-bearing tribo-layer is established. The tribo-layers are formed through the oxidation, agglomeration, compactness, and sintering of fine metallic debris under high pressures, and high temperatures are favored [2-4]. Hence, the oxide scale on the sliding surface of metals is beneficial to wear resistance. However, for high chromium stainless steels (STs), oxidation is inhibited significantly by the formation of a self-healing protective chromium layer $\left(\mathrm{Cr}_{2} \mathrm{O}_{3}\right.$ or $\left.\left(\mathrm{Fe}_{1-x} \mathrm{Cr}_{x}\right)_{2} \mathrm{O}_{3}\right)$ at high temperatures; this layer can prevent the outward diffusion of iron and inward diffusion of oxygen, thereby resulting in several problems during hot forming, such as the non-uniform wear of the tool and the sticking phenomenon. Furthermore, investigations into the tribological behaviors of ST are scarce.

The tribological behavior between ST and tools are governed by several factors and has received insignificant attention. Roy et al. [5] investigated the tribological behavior of PM 1000 alloy and 100Cr6 against 253MA alloy from room temperature to $1,073 \mathrm{~K}$ and discovered that transfer, mechanically mixed, and composite layers were formed in sequence with increasing temperature, where the 100Cr6/253MA tribo-pair did not form a transfer layer at room temperature. The wear of the 253MA alloy depended significantly on the oxidation characteristics of the mating surfaces. Cheng et al. [6, 7] investigated the friction and wear of high-speed steel (HSS) and FSS445 ferritic stainless steel by performing pin-on-disc tests at 850 and $900{ }^{\circ} \mathrm{C}$; the results showed that the formation of a $\mathrm{Cr}_{2} \mathrm{O}_{3}$ layer can reduce and stabilize the friction coefficient while causing abrasive wear to counter the HSS pin. Prior to the formation of $\mathrm{Cr}_{2} \mathrm{O}_{3}$, the HSS pin indicated dominant adhesive wear. Therefore, when used with ST, the desired tool materials shall present strong adhesion resistance prior to the formation of $\mathrm{Cr}_{2} \mathrm{O}_{3}$, as well as strong abrasion resistance when the $\mathrm{Cr}_{2} \mathrm{O}_{3}$ scale was established.

Ceramic tools are ideal candidates fulfilling the above-mentioned requirements; they are superior to HSS in terms of retaining excellent mechanical strength, high dimensional tolerances, strong oxidation resistances at high temperatures, and relatively low reactivities with iron $[8,9]$. These favorable properties render ceramic tools highly suitable for hightemperature tools such as isothermal forging dies, forming dies, metalworking rolls, cutting tools, and wire-drawing dies [10-12]. Wan et al. [13] investigated the friction and wear performances of four types of tool materials (GCr15, $\mathrm{ZrO}_{2}, \mathrm{SiC}$, and $\mathrm{Si}_{3} \mathrm{~N}_{4}$ ) against interstitial-free steels on a pin-on-disc tribometer using a load of $10 \mathrm{~N}$, a temperature of $800{ }^{\circ} \mathrm{C}$, and a linear velocity of $0.1 \mathrm{~m} / \mathrm{s}$. The results revealed that $\mathrm{SiC}$ and $\mathrm{Si}_{3} \mathrm{~N}_{4}$ produced higher friction coefficients but substantially lower wear rates; $\mathrm{SiC}$ and $\mathrm{Si}_{3} \mathrm{~N}_{4}$ presented wear losses of only $20 \%$ and $30 \%$ of those of $\mathrm{GCr} 15$ and $\mathrm{ZrO}_{2}$, respectively. The authors attributed the tribological behaviors of $\mathrm{SiC}$ and $\mathrm{Si}_{3} \mathrm{~N}_{4}$ to their excellent abrasion resistance and the formation of iron silicate compounds on their surfaces under high shear stresses and temperatures. However, based on literature survey conducted by the authors, ceramic materials are rarely tested against high-chromium ST at high temperatures.

In this study, the tribological behavior of three tool materials (high-speed steel, $\mathrm{Si}_{3} \mathrm{~N}_{4}$, and $\mathrm{SiC}$ ) against mild steel (MS) and high-chromium ST was investigated using a ball-on-disc tribometer at $900{ }^{\circ} \mathrm{C}$, in which the formation of oxide scale was a key variant. The formation of tribo-oxide and near-surface-transformed layers at elevated temperatures were analyzed using secondary electron microscopy (SEM), energydispersive X-ray (EDX), and three-dimensional (3D) surface profilometry, and their relation to friction and wear responses was interpreted.

\section{Materials and experimental details}

\subsection{Materials}

Three types of tool materials were tested in this study: the M50 HSS ball (manufactured by McMaster-Carr Co., Ltd., USA), a $\mathrm{Si}_{3} \mathrm{~N}_{4}$ ball (manufactured by Jiaxing Jienaier Cemented Carbides Co., Ltd., China), and a SiC ball (manufactured by Ketai Ceramic Co., Ltd., China). All three balls had a diameter of $6.3 \mathrm{~mm}$, and their mechanical properties are presented in Table 1. As shown in Table 1, both the hardness and Young's modulus increased in the order of $\mathrm{HSS}, \mathrm{Si}_{3} \mathrm{~N}_{4}$, and $\mathrm{SiC}$, whereas $\mathrm{Si}_{3} \mathrm{~N}_{4}$ indicated a higher fracture toughness than $\mathrm{SiC}$.

Atlas 253MA (developed by Avesta Polarit, Sweden) is an austenitic, chromium-nickel ST that offers excellent properties at high temperatures as well as ease of 
Table 1 Dimensions and mechanical properties of tested tool materials.

\begin{tabular}{cccc}
\hline $\begin{array}{c}\text { Tool } \\
\text { materials }\end{array}$ & $\begin{array}{c}\text { Hardness } \\
(\mathrm{GPa})\end{array}$ & $\begin{array}{c}\text { Young's } \\
\text { modulus } \\
(\mathrm{GPa})\end{array}$ & $\begin{array}{c}\text { Fracture } \\
\text { toughness } \\
\left(\mathrm{MPa} \cdot \mathrm{m}^{1 / 2}\right)\end{array}$ \\
\hline $\mathrm{HSS}$ & $6.2 \pm 0.2$ & $161.5 \pm 1.2$ & - \\
$\mathrm{Si}_{3} \mathrm{~N}_{4}$ & $19.5 \pm 0.9$ & $248.2 \pm 4.3$ & $6.5 \pm 0.5$ \\
$\mathrm{SiC}$ & $34.9 \pm 2.1$ & $304.7 \pm 2.9$ & $4.5 \pm 0.5$ \\
\hline
\end{tabular}

fabrication. It exhibits strong oxidation resistance up to $1,150{ }^{\circ} \mathrm{C}$ by forming a thin, highly adherent protective oxide [14]. Atlas 253MA can maintain high strengths at elevated temperatures, as shown in Table 2; therefore, it is often used in a wide range of industrial applications at temperatures ranging from 400 to $900{ }^{\circ} \mathrm{C}$. Some of these applications require high wear resistances at high temperatures. The chemical compositions of a few types of steels measured via optical emission spectrometry (Oxford Instruments PMI-MASTER, Germany) are listed in Table 3. MS was tested as a reference, and the chemical composition of which is listed in Table 3 as well.

\subsection{Tribological tests}

The tribological behavior of the designed tool/ST and tool/MS tribo-pairs was investigated using a rotary ball-on-disc tribometer (UMT TriboLab, Bruker, Germany) at high temperatures in an air atmosphere. The tribometer was designed with speeds of $0.1-$ $5,000 \mathrm{rpm}$ and a torque up to $5 \mathrm{~N} \cdot \mathrm{m}$. The test chamber was an electric heater wire furnace with a heating capacity of $1,000{ }^{\circ} \mathrm{C}$ and an accuracy of $\pm 1{ }^{\circ} \mathrm{C}$. Frictional sliding tests were performed after the furnace temperature was increased to $900{ }^{\circ} \mathrm{C}$ and stabilized for $5 \mathrm{~min}$. For the test, $900{ }^{\circ} \mathrm{C}$ was selected because the sticking problem of high chromium ST typically occurs at such a temperature, at which the weakest combination of tensile strength and scale thickness is generated [10]. Hence, the prevention of the sticking of tool/high-chromium ST near $900{ }^{\circ} \mathrm{C}$ should be emphasized. The oxidized MS and ST surfaces had a roughness of $2.5 \pm 0.4$ and $0.84 \pm 0.1 \mu \mathrm{m}$ prior to sliding, respectively. Ball-on-disc tribological tests were conducted at a linear speed of $0.1 \mathrm{~m} / \mathrm{s}$ and a normal load of $20 \mathrm{~N}$. To ensure repeatability, all tests were repeated at least thrice. As reported previously in Ref. [3], the ball and disc have different temperatures in the high-temperature ball-on-disc configuration; when the disc temperature was set to $900{ }^{\circ} \mathrm{C}$, the temperature of the ball only reached approximately $680{ }^{\circ} \mathrm{C}$. At the end of the sliding period, the motor and heating furnace were switched off, the ball was immediately removed from the furnace, and the disc was cooled in the furnace.

The mechanical properties and microstructure transformation of steels will deteriorate at elevated temperatures; in this regard, the austenitization point $\left(\mathrm{Ac}_{3}\right)$ is critical. The austenitization temperature is significantly affected by the alloy elements and contents. The empirical formula [15] to calculate $\mathrm{Ac}_{3}$ is as follows:

$$
\begin{aligned}
\mathrm{Ac}_{3}= & 902-255 \mathrm{C}-11 \mathrm{Mn}+19 \mathrm{Si}-5 \mathrm{Cr} \\
& +13 \mathrm{Mo}-20 \mathrm{Ni}+55 \mathrm{~V}
\end{aligned}
$$

where $\mathrm{Ac}_{3}$ denotes the upper equilibrium temperature $\left({ }^{\circ} \mathrm{C}\right)$ between ferrite and austenite. The austenitizing temperatures for MS and HSS were calculated to be approximately 860 and $780{ }^{\circ} \mathrm{C}$; this implies that the MS was is in the austenite state, whereas the HSS remained as a martensitic matrix.

Table 2 Mechanical properties of tested 253MA ST and MS at $900{ }^{\circ} \mathrm{C}[14,16,17]$.

\begin{tabular}{ccccc}
\hline & Yield strength $(\mathrm{MPa})$ & Ultimate tensile strength $(\mathrm{MPa})$ & Elongation $(\%)$ & Reduction in Area $(\%)$ \\
\hline $253 \mathrm{MA}$ & 79.3 & 169.6 & - & 92 \\
$\mathrm{MS}$ & 40 & 75 & 1.8 & - \\
\hline
\end{tabular}

Table 3 Measured chemical compositions of different steels (wt $\%$ ).

\begin{tabular}{ccccccccccccc}
\hline Type of steel & $\mathrm{C}$ & $\mathrm{Si}$ & $\mathrm{Mn}$ & $\mathrm{P}$ & $\mathrm{S}$ & $\mathrm{Cu}$ & $\mathrm{Ni}$ & $\mathrm{Cr}$ & $\mathrm{Mo}$ & $\mathrm{V}$ \\
\hline HSS & 0.825 & 0.25 & 0.25 & 0.0150 & 0.008 & 0.1 & 0.15 & 4.125 & 4.25 & 1 \\
$\mathrm{ST}$ & 0.0843 & 1.492 & 0.681 & 0.0274 & 0.0050 & 0.212 & 10.677 & 21.009 & - & - \\
$\mathrm{MS}$ & 0.1356 & 0.1795 & 0.695 & 0.0087 & 0.0235 & 0.1807 & 0.0528 & 0.1444 & - & - \\
\hline
\end{tabular}




\subsection{Characterization methods}

After performing high-temperature tribo-tests, the cross sections of the disc wear tracks were cut using a precision cut-off saw (Model Accutom-50, Struers, USA), hot mounted, and then cut again in the middle of the hot-mounted samples to ensure the good preservation of the brittle oxide scale.

The microstructures of the tested steels were observed via SEM after they were grounded, polished, and etched with $5 \%$ Nital $(300 \mathrm{~mL}$ of $\mathrm{HCl}, 15 \mathrm{~mL}$ of $\mathrm{H}_{2} \mathrm{O}_{2}$, and $100 \mathrm{~mL}$ of distilled water).

Macrohardness measurements were performed using a HXD-1000TMSC/LCD mode hardness testing device (Shanghai Taiming Co., Ltd., China) with a hold time of $15 \mathrm{~s}$ and a $10 \mathrm{~g}$ load. Microhardness tests were performed using a G200 Nano Indenter (KEYSIGHT, USA) and a Berkovich nanoindenter with a radius of $120 \mathrm{~nm}$. This equipment provides a loading capacity of $500 \mathrm{mN}$ and delivers a displacement of less than $0.01 \mathrm{~nm}$ and a load resolution of $50 \mathrm{nN}$. A load of $2 \mathrm{~g}$ was employed to measure at least five positions for the same material phase.

The oxidation behavior of grounded and polished ST (up to $1,050^{\circ} \mathrm{C}$ ) was analyzed using an in-situ hightemperature X-ray diffractometer (XRD, Ultima IV, Rigaku Corporation, Japan). XRD characterization was conducted at a scanning rate of $2\left(^{\circ}\right) / \mathrm{min}$ and a step size of $0.02^{\circ}$. The heating rate of the sample was $10{ }^{\circ} \mathrm{C} / \mathrm{min}$ and a hold time of $10 \mathrm{~min}$ was set prior to the test.

The worn scars on the balls were characterized via surface profilometry (Contour GT, Bruker, Germany) using Vision 64 software, and the wear tracks on the disc were analyzed using a Keyence VK-X100 laser scanning microscope. Both of these profilometers can be used to perform non-contact two-dimensional and 3D measurements of the profile and roughness of the worn surface as well as capture high-resolution images using precision $z$-axis control.

The cross-sectional micrographs and corresponding EDX analysis of the wear track were obtained using a JEOL JSM-6490L SEM microscope with a $30 \mathrm{kV}$ conventional tungsten filament; additionally, JEOL JSM-7500FA, which is a $30 \mathrm{kV}$ semi in-lens cold field emission gun SEM with a capability of 1.4 spatial resolution, was used to characterize the features at a higher resolution.

\section{Results}

\subsection{Microstructure and mechanical properties of tested steels}

The microstructures of the MS and ST tested are shown in Fig. 1. The MS is composed of bulky ferrite and pearlite, and the ST is composed of austenite. The microhardness of the ST and MS were $110.3 \pm 12.4$ and $117.7 \pm 14.7 \mathrm{HV}$ at room temperature, respectively.

\subsection{In-situ high-temperature XRD characterization of surface oxidation}

The ST was analyzed using an in-situ high-temperature XRD at various temperatures, as shown in Fig. 2(a). The results indicate the excellent anti-oxidation ability of the ST between 25 and $1,050{ }^{\circ} \mathrm{C}$, and weak peaks belonging to $\left(\mathrm{Fe}_{0.6} \mathrm{Cr}_{0.4}\right)_{2} \mathrm{O}_{3}$ were identified at $900{ }^{\circ} \mathrm{C}$,

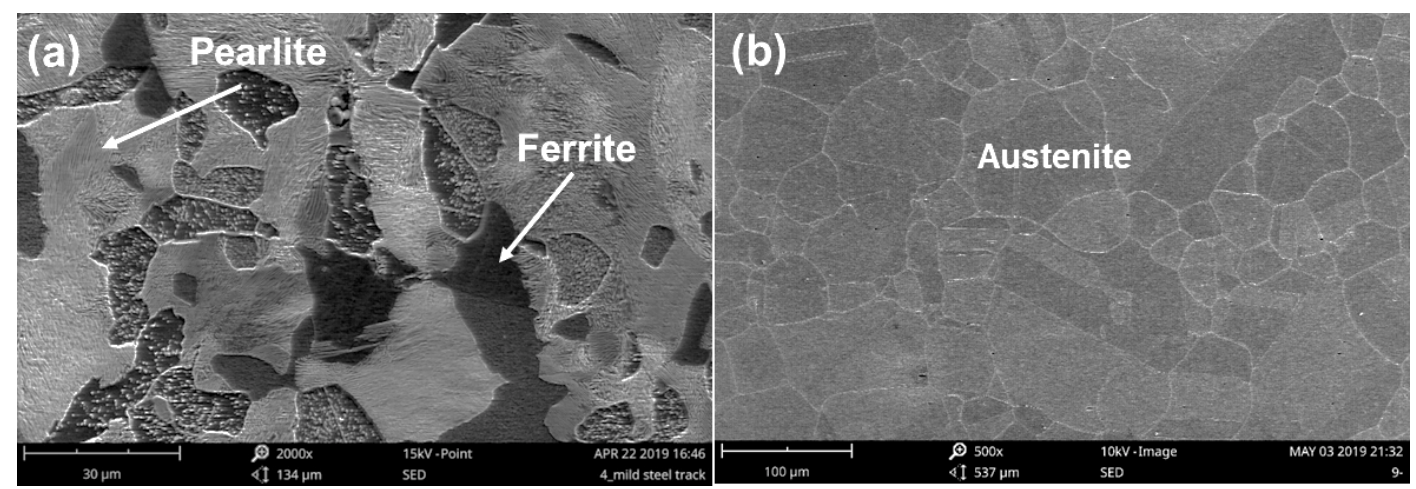

Fig. 1 SEM images of microstructures of tested materials: (a) MS and (b) high-chromium ST after being etched using 5\% Nital (300 mL of $\mathrm{HCl}, 15 \mathrm{~mL}$ of $\mathrm{H}_{2} \mathrm{O}_{2}$, and $100 \mathrm{~mL}$ water). 

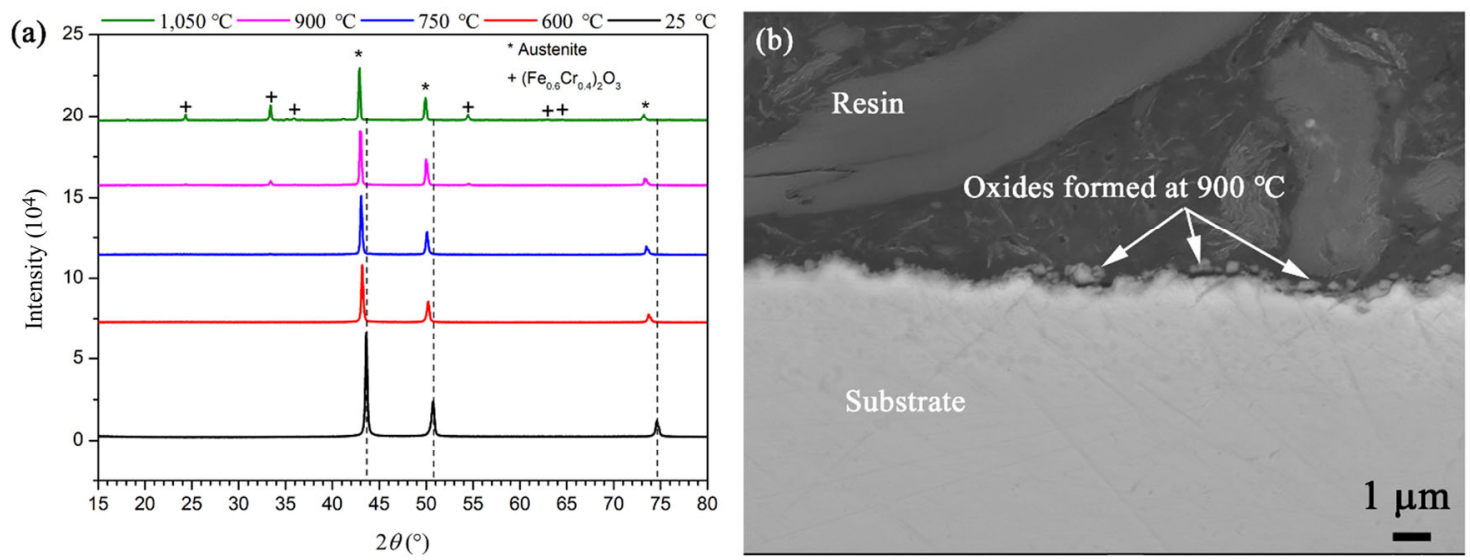

Fig. 2 (a) In-situ XRD patterns of tested ST surface at different temperatures and (b) cross-sectional SEM image of ST sample after being heated at $900{ }^{\circ} \mathrm{C}$.

below which only slight oxidation was detected. These peaks further developed when the temperature increased to $1,050{ }^{\circ} \mathrm{C}$. ST exhibits superior hightemperature oxidation resistance in dry oxidizing environments, primarily because of the formation of a Cr-rich surface oxide, $\alpha-\left(\mathrm{Fe}_{0.6} \mathrm{Cr}_{0.4}\right)_{2} \mathrm{O}_{3}$. The peak shifted to a smaller diffraction angle at a temperature higher than the room temperature owing to thermal expansion [18]. Figure 2(b) shows a cross-sectional SEM image of the static oxidized surface heated to $900{ }^{\circ} \mathrm{C}$, in which a discontinuous and extremely thin oxide layer $(<1 \mu \mathrm{m})$ was observed. Based on the results shown in Fig. 2(a), these oxides were primarily composed of $\left(\mathrm{Fe}_{0.6} \mathrm{Cr}_{0.4}\right)_{2} \mathrm{O}_{3}$.

\subsection{Friction curves}

Figure 3 shows the representative frictional curves and mean friction coefficients averaged in the stable sliding period using different tool materials against MS and ST. For all the tribo-pairs, a transition from the running-in stage with a high and fluctuating friction coefficient to the steady-state stage was observed, accompanied by a progressive reduction in the friction coefficient owing to the gradual development of the stable tribo-layer [19]. The HSS and $\mathrm{Si}_{3} \mathrm{~N}_{4}$ were more sensitive to the other steel grades than $\mathrm{SiC}$ during high-temperature sliding. HSS produced a higher friction coefficient with MS than with ST, whereas $\mathrm{Si}_{3} \mathrm{~N}_{4}$ exhibited an opposite performance. The SiC generated similar friction curves in the stabilizing stage, regardless of the grade of the disc steels; the SiC/ST tribo-pair exhibited significantly fluctuating friction.

The ball/ST tribo-pairs had substantially higher friction coefficients than the ball/MS tribo-pairs during the running-in stage. This is primarily attributed to the differences in the morphology, composition, and properties of the contacting interface. For ball/MS, prior to sliding, the MS surface was shielded by an $88-\mu \mathrm{m}$-thick oxide scale with a surface roughness of $2.5 \pm 0.4 \mu \mathrm{m}$. This scale was composed of three layers (top $\mathrm{Fe}_{2} \mathrm{O}_{3}$, medium $\mathrm{Fe}_{3} \mathrm{O}_{4}$, and bottom $\mathrm{FeO}$ ) [3]. For ball/ST, a discontinuous and extremely thin oxide layer $(<1 \mu \mathrm{m})$ was observed on the ST surface with a surface roughness $\left(R_{a}\right)$ of $0.84 \pm 0.1 \mu \mathrm{m}$. This oxide was primarily composed of spinel $\left(\mathrm{Fe}_{0.6} \mathrm{Cr}_{0.4}\right)_{2} \mathrm{O}_{3}$, as shown by the XRD patterns in Fig. 2(b). A further analysis of the running-in period revealed that the highest friction coefficients generated by the ball/ST tribo-pairs (1.0-1.1) were nearly twice larger than those of the ball/MS tribo-pairs (0.5-0.6), apart from some random friction peaks. This implies that the ball/ST interfaces were subjected to approximately twice the shear stress of the ball/MS interfaces, and this might cause mechanical damage to the ball/ST contacting surfaces. This phenomenon is associated with the initial surface state of the disc prior to sliding, where a thick oxide scale on the MS disc and a substantial amount of oxide on the ST disc were observed. Furthermore, the friction coefficients for SiC and $\mathrm{Si}_{3} \mathrm{~N}_{4}$ increased momentarily at approximately 530 and $458 \mathrm{~s}$, respectively. These momentary increases in friction with ceramic tribo-pairs have been reported to be associated with grain pull-out wear [20], whereas 

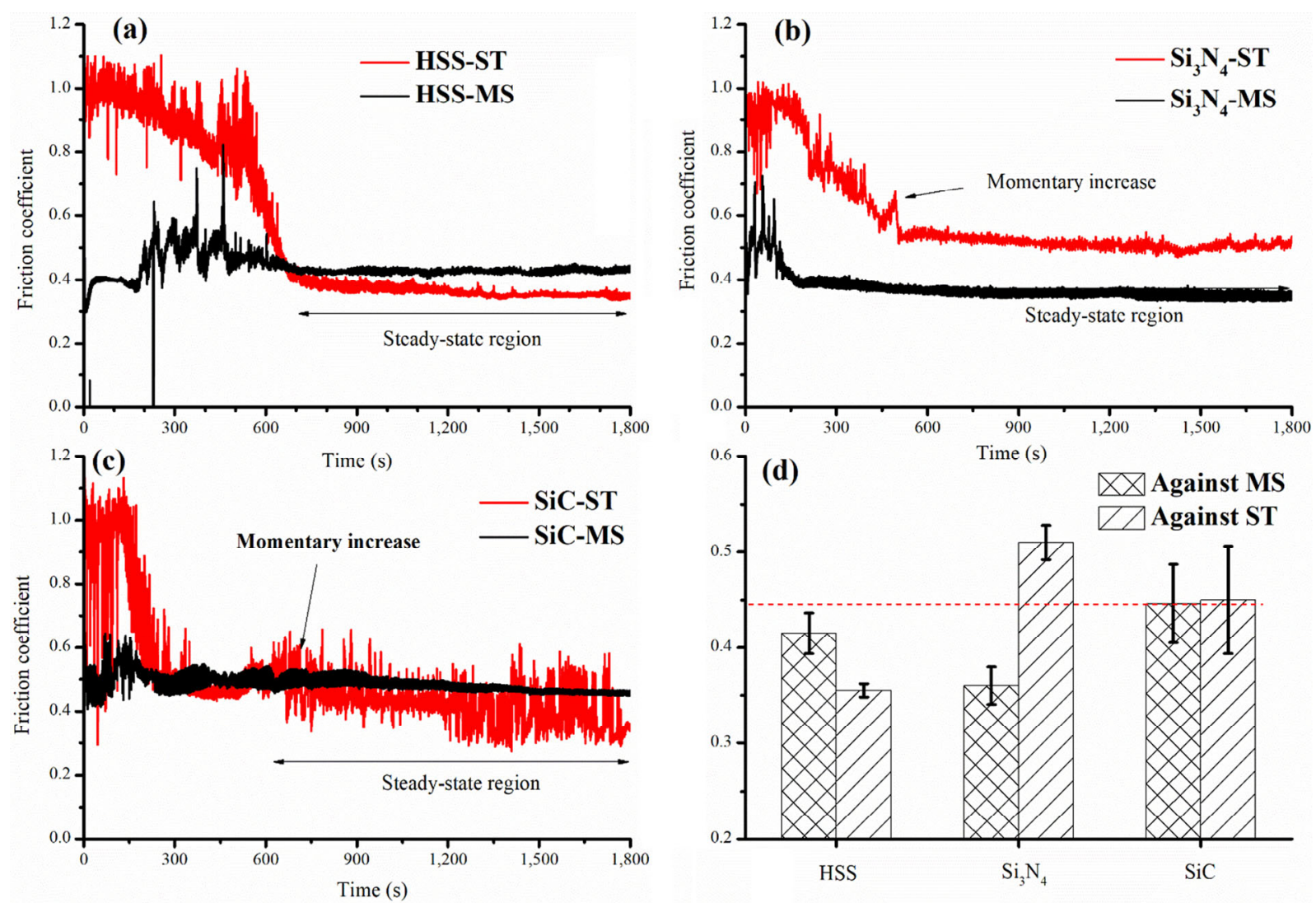

Fig. 3 Representative frictional curves generated by different tribo-pairs: (a) HSS; (b) $\mathrm{Si}_{3} \mathrm{~N}_{4}$; (c) SiC ball material against MS and ST; (d) mean friction coefficients calculated during steady-state sliding period tested at $900{ }^{\circ} \mathrm{C}, 0.1 \mathrm{~m} / \mathrm{s}$, and $20 \mathrm{~N}$.

these transition features were not observed in cases involving sliding against MS discs.

Figure 3(d) shows the mean friction coefficients calculated from the period of stable sliding. Against the MS, SiC yielded the highest mean friction coefficient, followed by the HSS ball, whereas $\mathrm{Si}_{3} \mathrm{~N}_{4}$ produced the lowest friction. In contrast to the $\mathrm{ST}$, the $\mathrm{Si}_{3} \mathrm{~N}_{4}$ ball generated the highest mean friction coefficient, followed by the SiC ball, whereas the HSS yielded the lowest friction. These results show that ceramic tools typically generated higher friction coefficients than the HSS tools in the relative motion between the tool and ST workpiece at high temperatures, and the frictional response was related significantly to the type of ceramic tool.

\subsection{SEM micrographs of worn morphology}

\subsubsection{HSS balls against MS/ST}

Figure 4 shows SEM micrographs of the morphology of the worn surfaces on the HSS balls and mating discs. When rubbing against the MS disc, the HSS ball presented severe abrasive wear with two deep grooves at two edges, as shown in Fig. 4(a). This indicates that the HSS at high temperatures was abraded severely by the hard oxide ridges on the MS track because of thermal softening, as indicated by the dashed red lines in Fig. 4(a). Metal lumps attached to the ball scar in rough shapes were observed, and they experienced repeated plastic deformation during sliding. Large amounts of oxide debris were observed in the wear track of the disc, as shown in Fig. 4(b). Figure 4(c) shows the corresponding cross-section of the wear track shown in Fig. 4(b), revealing that the homogeneous oxide scale in the non-contact zone had a thickness of $88 \pm 1 \mu \mathrm{m}$ after heating at $900{ }^{\circ} \mathrm{C}$ for $35 \mathrm{~min}$; subsequently, it reduced to an average thickness of $84 \pm 6 \mu \mathrm{m}$ in the wear track. The oxide in the track exhibited a layered structure, where the top layer was cracked and the bottom layer was compact, suggesting a distinction between the initial oxide scale and the tribo-oxide (glaze) layer formed during sliding, as 


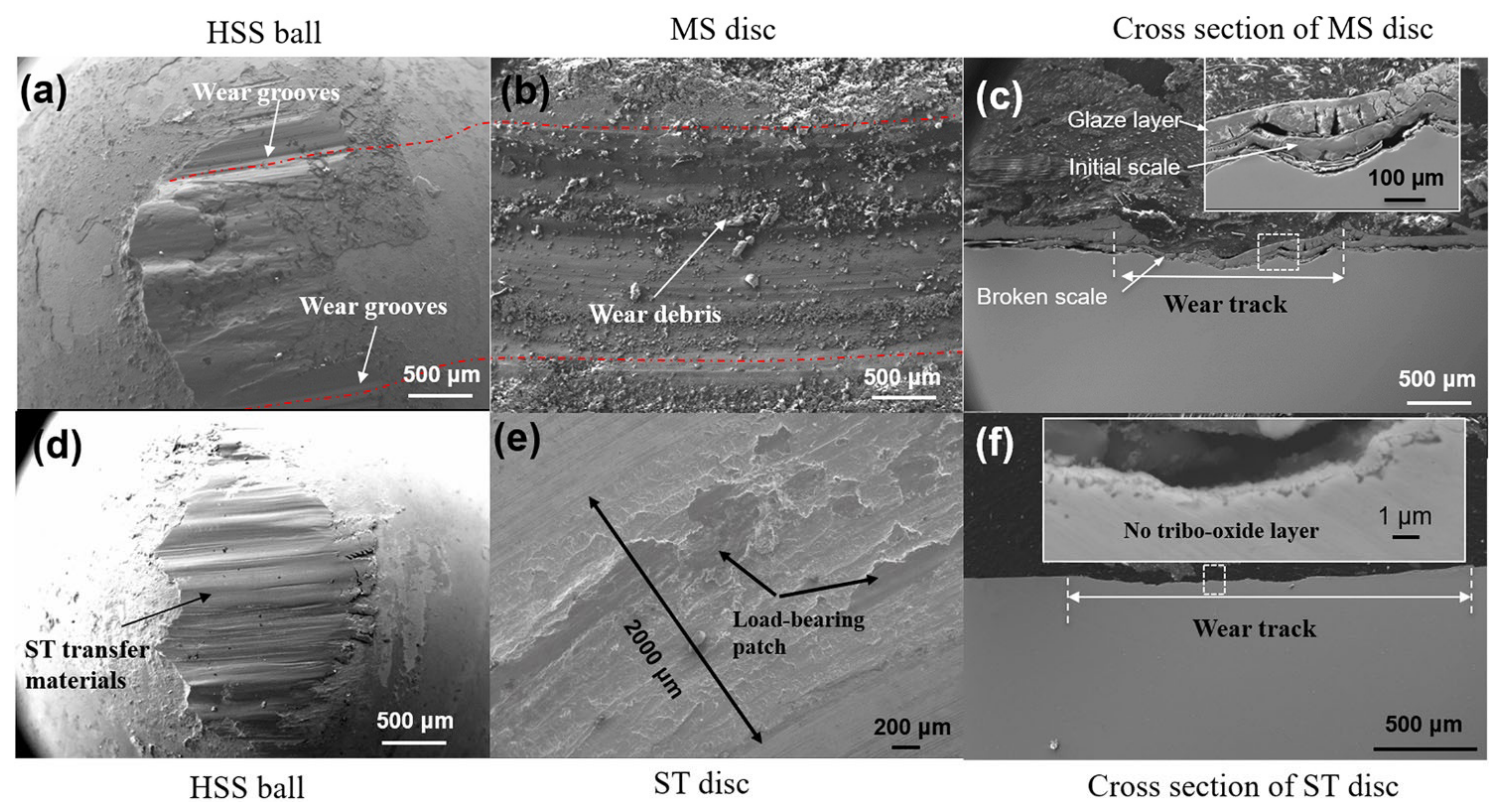

Fig. 4 SEM micrographs of worn scars on balls and discs, and corresponding cross-sectional images of disc tracks: (a-c) for HSS ball -MS disc; (d-f) for HSS ball-ST disc tested at $900{ }^{\circ} \mathrm{C}, 0.1 \mathrm{~m} / \mathrm{s}$, and $20 \mathrm{~N}$.

shown in Fig. 4(c). Furthermore, an inhomogeneous coverage by the glaze layer was observed, implying that the underlying scale was exposed as the top layer was removed, thereby resulting in an increased material removal rate.

When rubbing against the ST, the HSS scar was entirely shielded by a thick layer of ST fragments. The worn surface on the corresponding disc exhibited a heavily deformed, highly worn, and torn morphology with some smooth load-bearing patches, indicating a direct metal-to-metal adhesive wear. The cross-sectional image in Fig. 4(f) suggests that an extremely thin protective glaze layer $(0.64 \pm 0.2 \mu \mathrm{m})$ was formed during sliding. This resulted in a high level of adhesion, material transfer, and production of large flat debris, which typically cause the sticking phenomenon in the hot metal forming of high-chromium ST. Furthermore, a negligible oxide scale was discovered in the noncontact zone, which underwent static oxidation at $900{ }^{\circ} \mathrm{C}$ for $35 \mathrm{~min}$.

\subsection{2 $\mathrm{Si}_{3} \mathrm{~N}_{4}$ ball against MS/ST}

Figure 5 shows SEM micrographs of the morphology of the worn surfaces on the $\mathrm{Si}_{3} \mathrm{~N}_{4}$ balls and mating discs. When rubbing against MS, the $\mathrm{Si}_{3} \mathrm{~N}_{4}$ ball experienced mild abrasive wear and showed a considerably smooth wear scar. $\mathrm{Si}_{3} \mathrm{~N}_{4}$ showed a slight decline in mechanical properties at $900{ }^{\circ} \mathrm{C}$ [21], whereas the MS exhibited a significant decline. Owing to the significant difference in hot hardness, the ceramic can deform and break the oxide asperities on the MS disc surface, thereby resulting in significant amounts of wear debris. The cross section of the wear track on the disc shown in Fig. 5(c) indicates that a thick tribo-oxide layer was formed. Furthermore, the oxide scale at the two sides of the wear track bowed up because of the pressure from the squeeze of the ball, revealing some extent of plastic deformation of the oxide scale, which is consistent with the claim that iron oxide possesses plastic deformation ability above $900{ }^{\circ} \mathrm{C}$ [22].

When rubbing against the ST, the worn surface on the ball experienced severe wear and formed many valleys and a network of cracks, of which the largest depth was $540 \mu \mathrm{m}$. The formation of cracks on ceramics is associated with the intrinsic low fracture toughness $\left(K_{\mathrm{IC}}=6-7 \mathrm{MPa} \cdot \mathrm{m}^{1 / 2}\right)$ owing to the low yield of strong covalent and ionic bonding [23]. The corresponding wear track on the disc indicated material loss through delamination wear, where a significant number of sheet-like flakes were generated. During rubbing, the ST surface was subject to repeated and accumulated plastic shear deformation under periodical loading actions, cracks nucleated at a certain depth below the surface and then further developed and propagated 


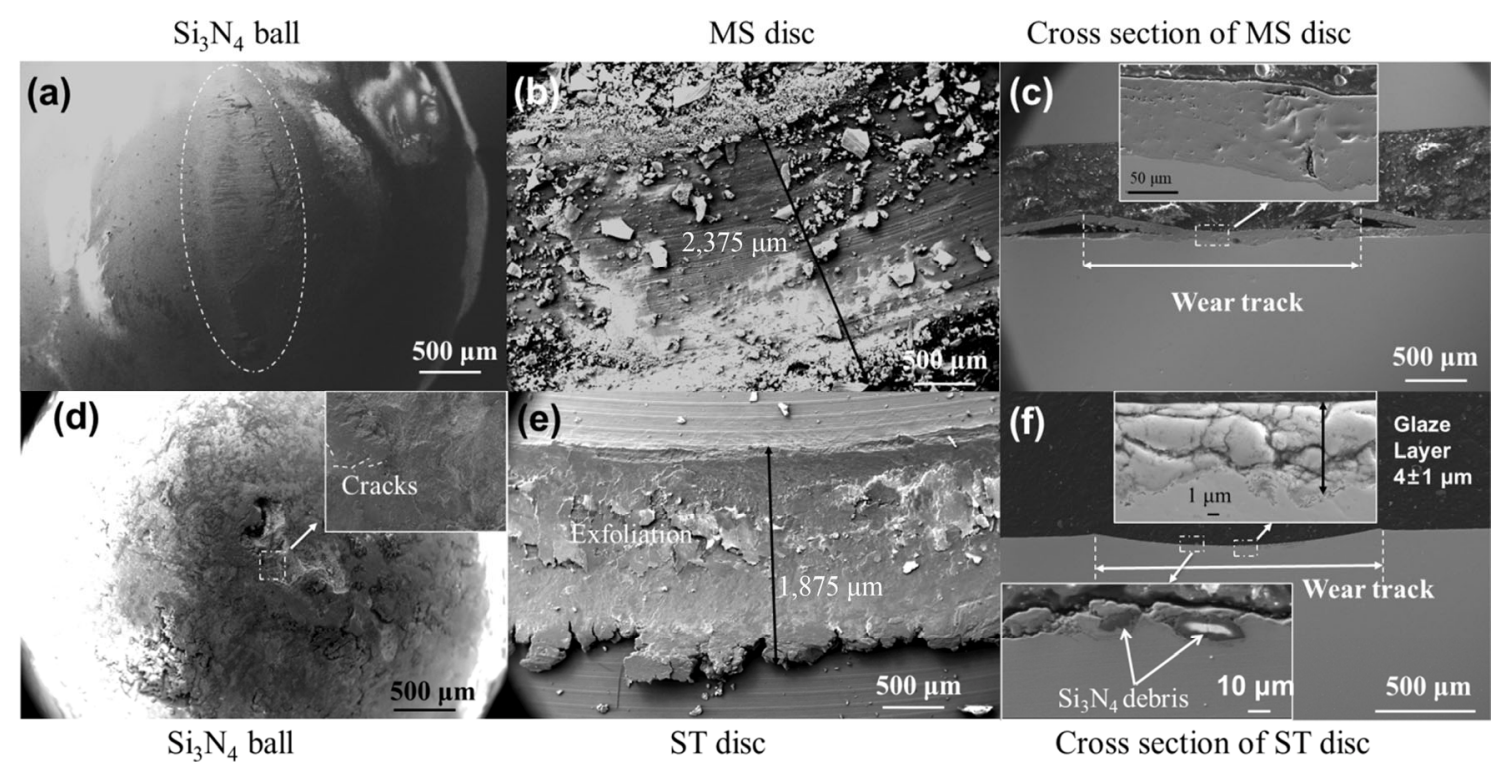

Fig. 5 SEM micrographs of worn scars on ball, disc, and corresponding cross-section of disc track: (a-c) for $\mathrm{Si}_{3} \mathrm{~N}_{4}-\mathrm{MS}$; $(\mathrm{d}-\mathrm{f})$ for $\mathrm{Si}_{3} \mathrm{~N}_{4}-\mathrm{ST}$ tested at $900{ }^{\circ} \mathrm{C}, 0.1 \mathrm{~m} / \mathrm{s}$, and $20 \mathrm{~N}$.

parallel to the surface, and long and thin wear sheets formed when the cracks sheared to the surface [24]. The corresponding cross-sectional image in Fig. 5(f) reveals that a glaze layer (thickness $4 \pm 1 \mu \mathrm{m}$ ) had formed on the worn surface of the disc. This layer can prevent the direct contact between the tool and ST substrate, thereby reducing the severe abrasive wear generated by the plow of the soft ST by hard ceramic asperities; furthermore, mild oxidational wear will occur when the tribo-oxide layer is established, as shown in Figs. 5(b) and 3(c). $\mathrm{Si}_{3} \mathrm{~N}_{4}$ debris was discovered at the bottom of the tribo-oxide layer, as shown in the inset of Fig. 5(f). This indicates that the wearoff of these $\mathrm{Si}_{3} \mathrm{~N}_{4}$ debris occurred primarily at the initial stage of sliding and was caused by the heavy shear stress in the running-in period. These findings were consistent with the friction transition to pull-out wear behavior shown in Fig. 3(b).

\subsubsection{SiC ball against MS/ST}

Figure 6 shows SEM micrographs of the morphologies of the worn surfaces on the SiC balls and steel discs. The SiC ball against the MS in Fig. 6(a) shows a morphology similar to that of $\mathrm{Si}_{3} \mathrm{~N}_{4}$, where mild abrasive wear is indicated. When rubbing against the ST shown in Fig. 6(d), the SiC ball scar showed a similar severe wear with many valleys and cracks; however, they were much shallower than those of the $\mathrm{Si}_{3} \mathrm{~N}_{4}$ ball. The worn surface on the disc shown in Fig. 6(e) indicated characteristics of delamination wear with many peeling-offs after a severe plastic deformation. The cross-sectional image in Fig. 6(f) shows that a thick glaze layer was established in the track, with the thickest layer reaching $21 \mu \mathrm{m}$. Thick plastically deformed ST, which was extruded from the central area of the track, was observed at the two sides of the wear track. At the bottom, some SiC wear debris were discovered, as shown in the inset of Fig. 6(f), similar to the phenomenon of $\mathrm{Si}_{3} \mathrm{~N}_{4}$; this suggests that the fracture of $\mathrm{SiC}$ primarily occurred at the early stage of sliding.

After the tribological tests were performed, the wear debris were collected and compared with the smaller debris (diameter: $128 \pm 57 \mu \mathrm{m}$ ) generated against the MS. Meanwhile, the ST wear particles tended to be larger and flatter, with an average diameter of up to $939 \pm 333 \mu \mathrm{m}$. This indicates that the ST debris had better ductility than the oxide scale on the MS surface, rendering it difficult to be refined and sintered. When rubbing against the ST disc, severe wear occurred on the HSS/ST tribo-pair; the material transferred continuously to the HSS surface to form a transfer layer, whereas that of the ST disc was severely plastically deformed and showed severe tearing marks. By contrast, when ceramics were used, the corresponding wear tracks on the disc showed a smooth scar. The results 


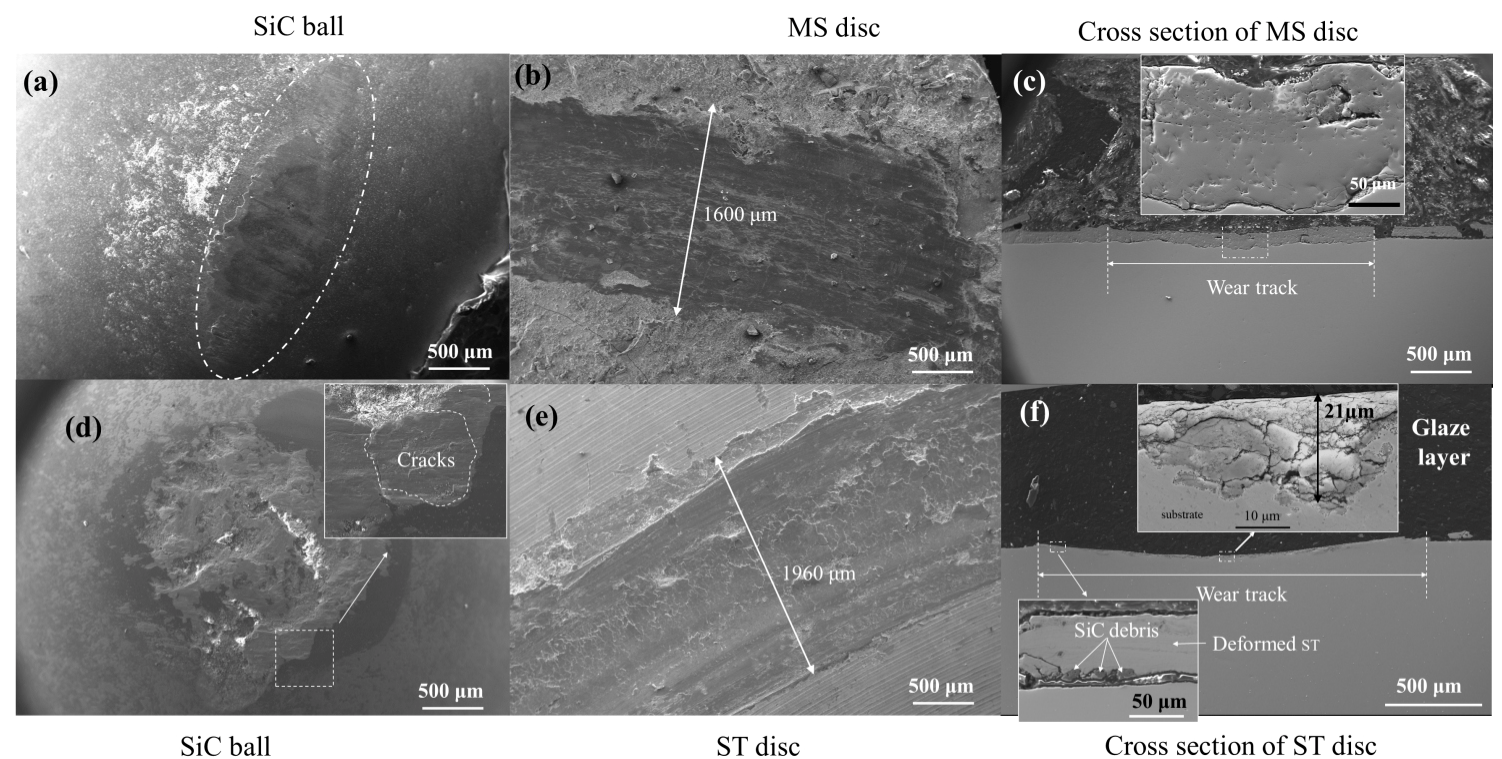

Fig. 6 SEM micrographs of worn scars on balls, discs, and corresponding cross-sectional images of disc tracks: (a-c) for SiC-MS; (d-f) for SiC/ST tested at $900{ }^{\circ} \mathrm{C}, 0.1 \mathrm{~m} / \mathrm{s}$, and $20 \mathrm{~N}$.

show that the ceramic tool was superior to the HSS tool when deforming MS; however, the ceramic surfaces deteriorated severely when deforming ST.

\subsection{Worn volume estimation}

Figure 7 shows the calculated wear volumes of the balls and discs under different tribological combinations. The insets in Figs. 7(b) and 7(d) show the methods used to calculate the worn volumes, in which the valley volume of the entire ball scar with the non-contact zone as the benchmark was measured via light profilometry. For the wear track on the disc, a wear track with a length of $557 \mu \mathrm{m}$ was included for each measurement, and the cross-sectional area was then calculated. The average value was calculated after three random measurements for each disc. Vision 64 software was used to process the data after the removal of the sphere and plane tilt.

When rubbing against the MS, the wear volume of the HSS ball was the highest, followed by those of the $\mathrm{SiC}$ ball and the $\mathrm{Si}_{3} \mathrm{~N}_{4}$ ball, as shown in Fig. 7(a). Furthermore, the calculations indicated that the worn volumes of $\mathrm{Si}_{3} \mathrm{~N}_{4}$ and $\mathrm{SiC}$ were 48 and 11 times lower than those of the HSS, respectively, owing to the retainability of mechanical properties at high temperatures. Moreover, the worn surfaces of $\mathrm{Si}_{3} \mathrm{~N}_{4}$
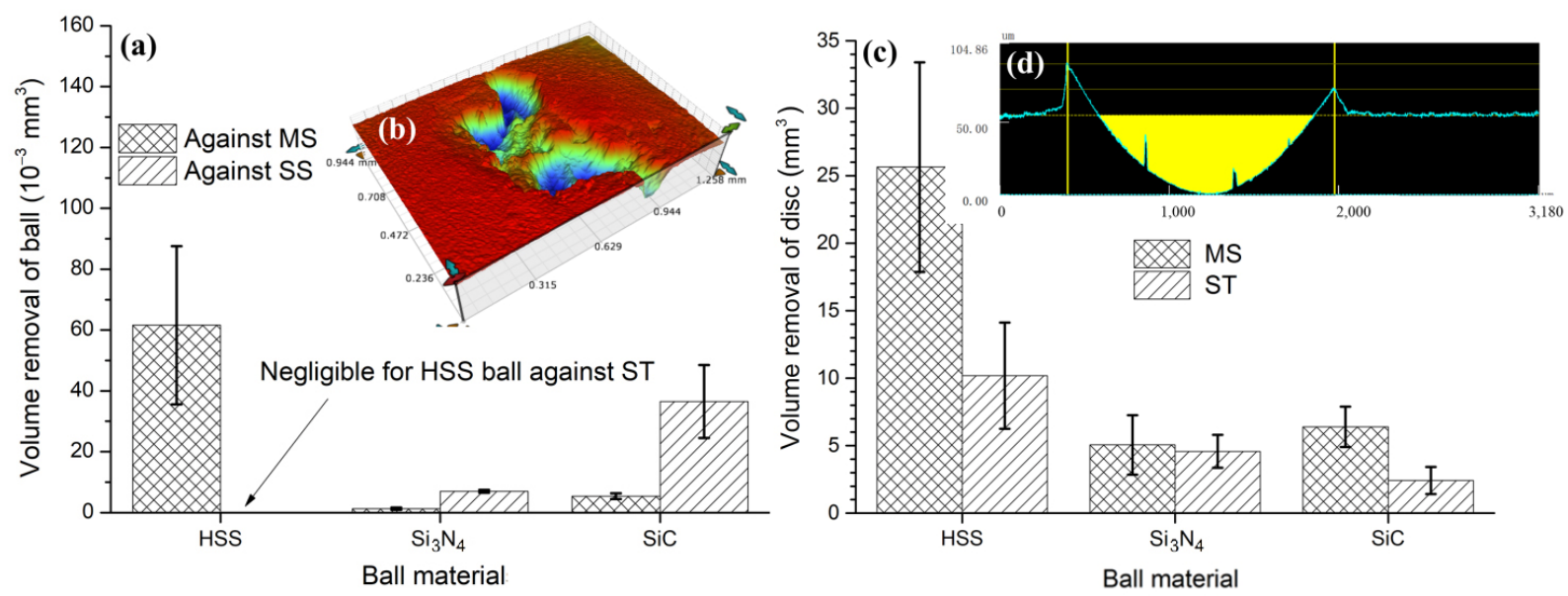

Fig. 7 Worn volumes obtained via light profilometry for (a) balls and the method to measure their volume loss; (c) discs and (d) the method to measure their volume loss tested at $900{ }^{\circ} \mathrm{C}, 0.1 \mathrm{~m} / \mathrm{s}$, and $20 \mathrm{~N}$. 
and $\mathrm{SiC}$ were smoother than that of the HSS.

When sliding against the ST disc, the $\mathrm{SiC}$ ball was subject to a significant volume loss, whereas $\mathrm{Si}_{3} \mathrm{~N}_{4}$ was subject to a lower volume loss because the HSS was entirely shielded by the counterface ST materials; hence, the worn volume of $\mathrm{Si}_{3} \mathrm{~N}_{4}$ was negligible. For the worn volumes of discs shown in Fig. 7(b), the MS experienced a higher worn volume than the ST. This is because the specific chemical composition of $\mathrm{Si}, \mathrm{N}$, and $\mathrm{Ce}$ in the 253MA heat-resistant alloy afforded excellent high-temperature strength [25], which is consistent with the results obtained by Archard and Hirst [26], i.e., ST always exhibits a lower removed volume than MS even though a higher load is exerted on the former.

\subsection{Near surface and nanoindentation characteri- zation}

\subsubsection{For MS disc against different counterface materials}

Figure 8 shows the optical cross-sectional images of wear tracks on MS discs after the sliding tests against different counterfaces. As shown in Fig. 8, the oxide scale can be segmented into two layers by the different contrast caused by their crystallographic differences: the top bright and shiny glaze layer formed by tribo-oxidation during sliding, and the bottom dark initial oxide scale formed by static oxidation during heating. The microhardness measured via nanoindentation, as shown in Fig. 8(d), suggesting that these two types of oxides possess significantly different microhardness values $(16.1 \pm 0.5 \mathrm{GPa}$ for glaze layer and $6.2 \pm 0.2 \mathrm{GPa}$ for initial scale) and Young's moduli $(246.6 \pm 9.8 \mathrm{GPa}$ for glaze layer and $138.3 \pm 19.3 \mathrm{GPa}$ for initial scale). The indentation depths at the maximum load for the substrate, initial scale, and glaze layer were 494.5, 367, and $259.7 \mathrm{~nm}$, respectively, and their residual depths after load removal were 432.7, 264.3, and $140.7 \mathrm{~nm}$, respectively. This indicates superior mechanical properties to the glaze layer in terms of abrasion resistance. Furthermore, the counterfaces did not significantly affect the mechanical properties of the glaze layer under the same sliding conditions, as shown in Fig. 8(d). It was also discovered that, for the disc wear track rubbing against the HSS ball shown in Fig. 8(a), the central part of the protective glaze layer was fractured and worn out, causing the underlined material to be unprotected; this resulted in the highest volume loss, as shown in Fig. 7(b). This phenomenon indicates that the applied load $(20 \mathrm{~N})$ exceeded the maximum load bearable by the glaze layer, thereby resulting in considerable spalling on
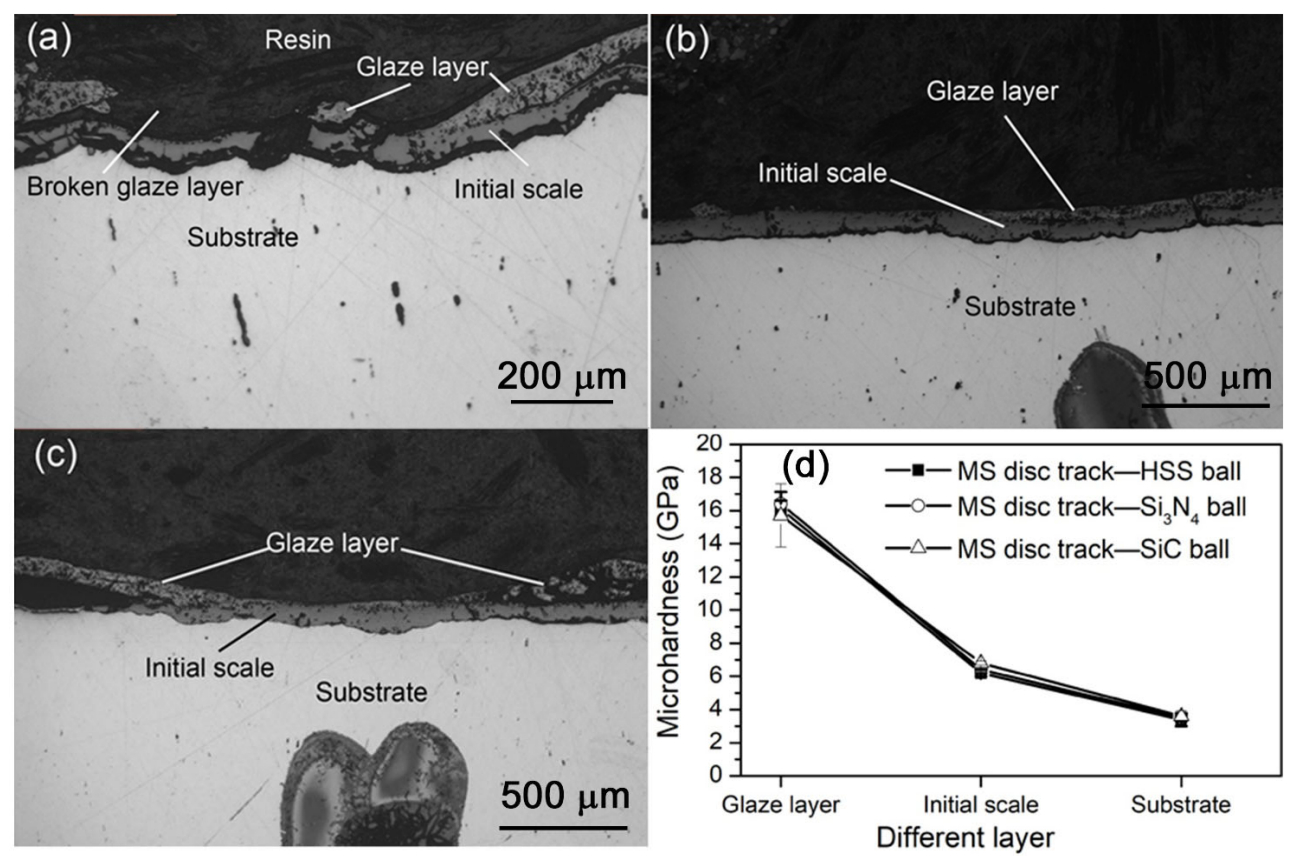

Fig. 8 Cross-sectional optical micrographs of wear tracks on MS discs against different types of balls: (a) HSS, (b) $\mathrm{Si}_{3} \mathrm{~N}_{4}$, and (c) $\mathrm{SiC}_{\text {; }}$ (d) microhardness of tribo-oxide glaze layer, initial scale formed during heating, and substrate of wear track on mild steel disc. 
the oxide layer [2]. By contrast, the other two wear tracks rubbing against the ceramic balls remained almost intact without severe damage and presented an inhomogeneous coverage of the worn surface, as shown in Figs. 8(b) and 8(c), resulting in a considerably low volume loss on the MS disc.

\subsubsection{For ST disc against different counterface materials}

Figure 9 shows the effect of the counterface materials on the microstructure variation of the subsurface on the ST disc wear track. As shown in Fig. 9, a plastically deformed layer was generated with the oxide glaze layer on top. The depth of the plastically deformed layer differed among these tribo-pairs, in which the ST with HSS exhibited the thinnest deformed layer measuring $17.3 \pm 2.4 \mu \mathrm{m}$. The ceramic balls can produce a much deeper plastically deformed layer on the
ST discs with the $\mathrm{Si}_{3} \mathrm{~N}_{4}$ and $\mathrm{SiC}$ balls, i.e., $62.4 \pm 3.8$ and $48.4 \pm 4.0 \mu \mathrm{m}$, respectively. It was discovered that the scale/substrate interface against the ceramics with deep grooves on the substrate was more convoluted compared with that against the HSS, which was fairly smooth, as shown in Fig. 9(a). These grooves have been reported to contribute significantly to the entrapment of wear debris particles [2].

Figure 10(a) shows the correlation between the worn volume and tribo-oxide thickness on the ST disc. As shown in Fig. 10, a thicker tribo-oxide is associated with a lower volume loss of the ST disc with an average thickness ranging between 1.2 and 13. This finding reveals that an increase in the thickness in the range of $1.2-13 \mu \mathrm{m}$ can reduce the wear of ST. Furthermore, ceramics can generate a thicker tribo-oxide layer on the ST mating surface. Figure 10(b) presents

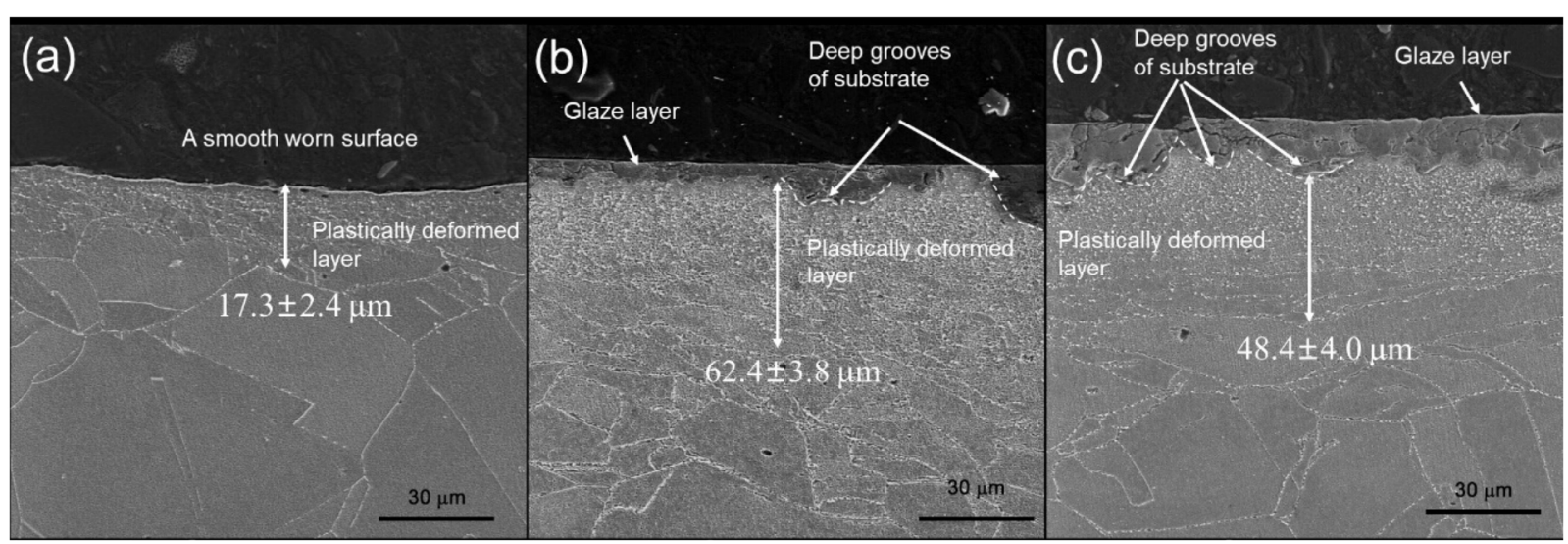

Fig. 9 SEM micrographs of cross-sections of wear tracks on ST disc against different counterface materials: (a) HSS, (b) $\mathrm{Si}_{3} \mathrm{~N}_{4}$, and (c) $\mathrm{SiC}$.
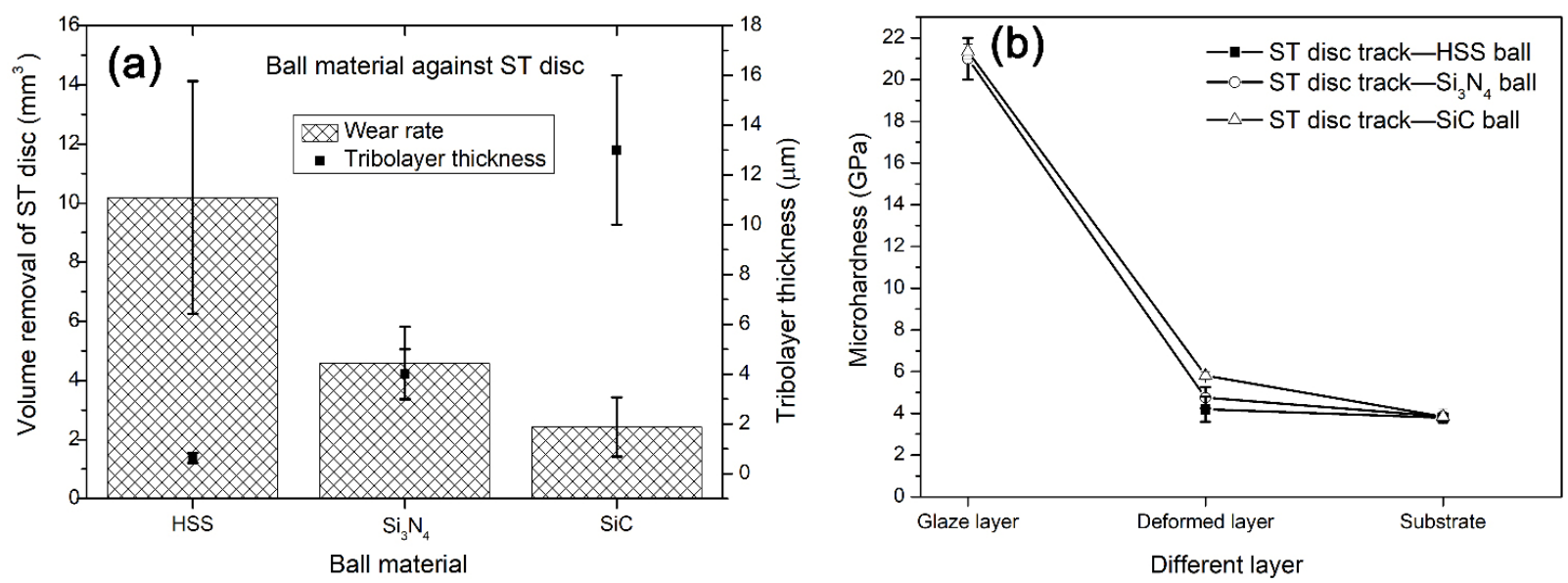

Fig. 10 (a) Correlation between tribo-layer thickness and worn volume on the wear track of ST disc and (b) microhardness of different layers in the subsurface. 
the microhardness of the different layers shown in Fig. 9. As shown in Fig. 10(b), the hardness of the glaze layer (approximately $21 \mathrm{GPa}$ ) was superior to that of the ST substrate (approximately 3.8 GPa). Furthermore, the microhardness of the deformed layer on ST depended on the counterface ranking against $\mathrm{SiC}, \mathrm{Si}_{3} \mathrm{~N}_{4}$, and HSS at 5.8, 4.8, and $4.2 \mathrm{GPa}$, respectively. The indentation depths at the maximum load for the substrate, initial scale, and glaze layer were $467.8,370.5$, and $246.7 \mathrm{~nm}$, respectively, and their residual depths were 405.7, 284.9, and $108.8 \mathrm{~nm}$, respectively. The establishment of a hard glaze layer with a plastically deformed and hardened layer supporting it can result in low friction and wear, and this deformation in ST will result in a work-hardened surface layer with grooves that can trap wear debris [2].

\subsection{EDX analysis of tribo-oxide layer on ST disc}

Figure 11 shows the cross-sectional backscatter electron images and EDX mappings of wear tracks on the ST discs for different tribological combinations. For the $\mathrm{HSS} / \mathrm{ST}$, an extremely thin oxide layer with $\mathrm{O}, \mathrm{Ni}$, Si,
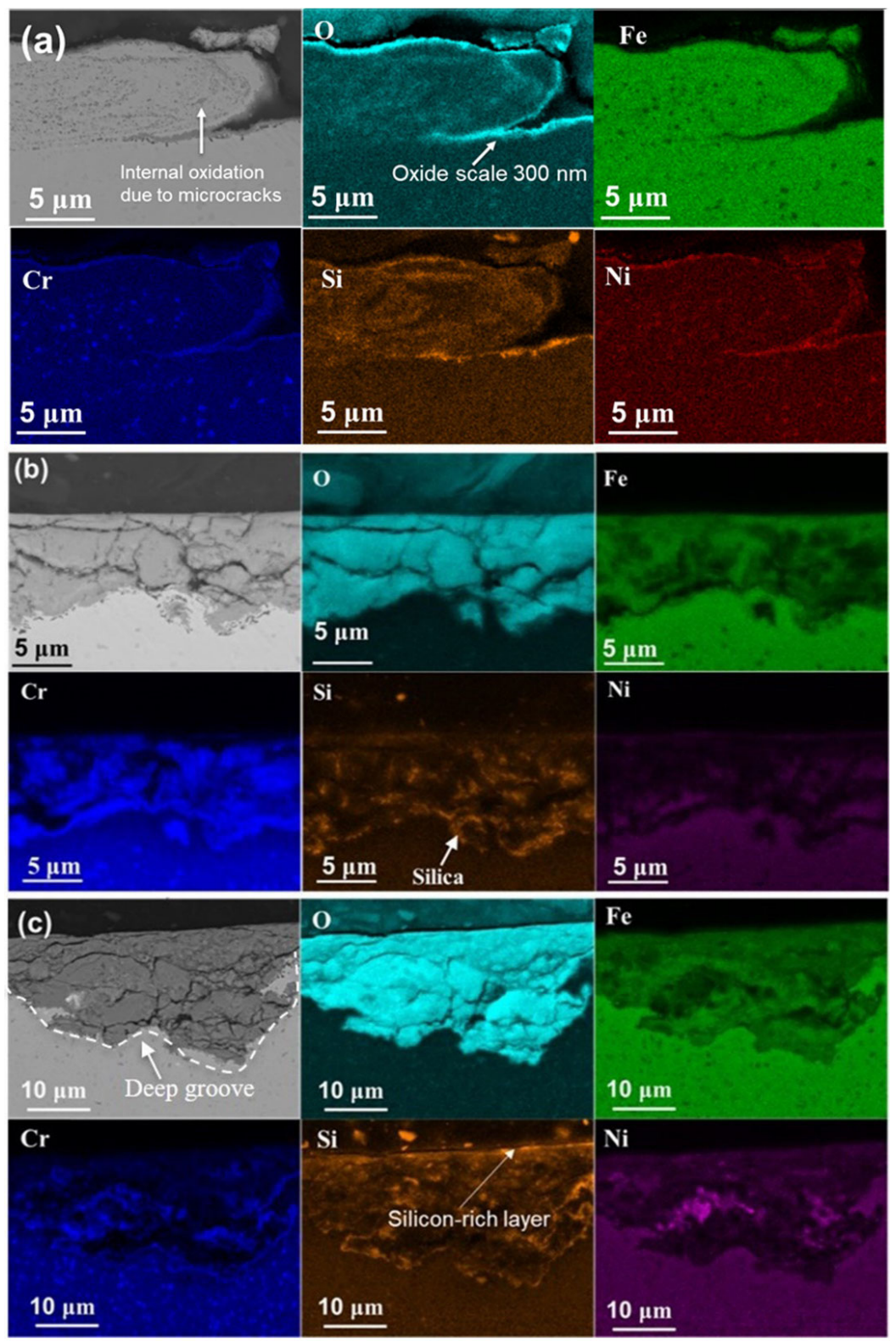

$\mathrm{Fe}$

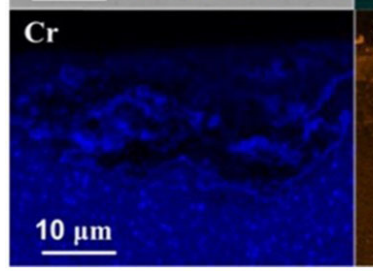

Fig. 11 Backscatter electron image and EDX mappings of central area of cross section of disc wear tracks of (a) HSS/ST, (b) Si $\mathrm{N}_{4} / \mathrm{ST}$, and (c) $\mathrm{SiC} / \mathrm{ST}$ tribo-pair at $900{ }^{\circ} \mathrm{C}, 20 \mathrm{~N}$, and $0.1 \mathrm{~m} / \mathrm{s}$. 
$\mathrm{Cr}$, and slight Fe was detected at the top of the wear track, where the formation of Si-rich oxide at the scale base can promote the adhesion of the scale to the metal substrate [27]; such a silicon oxide layer was observed in all the ST wear tracks, as shown in Figs. 11(a)-11(c). Furthermore, it was discovered that oxidation occurred in the near subsurface owing to the formation of microcracks after repetitive plastic deformation when the plastic deformation exceeded the limit of the ST ductility; these microcracks provided pathways for oxygen diffusion.

For the $\mathrm{Si}_{3} \mathrm{~N}_{4} / \mathrm{ST}$ shown in Fig. 11(b), a thick tribooxide layer with many cracks was observed. Two phases reflecting different chemical compositions were identified. One was Fe rich and located predominantly at the top, whereas the other was a Cr-rich solid solution with a slight amount of Fe. At the scale/metal interface, $\mathrm{Cr}_{2} \mathrm{O}_{3}$ with a small amount of $\mathrm{Fe}$ in solid solution underlined by $\mathrm{SiO}_{2}$ was discovered; it served as a self-healing oxidation resistance layer that protected the metal substrate from oxidation.

For the SiC/ST tribo-pair shown in Fig. 11(c), a similar morphology of the thick scale was observed, the thick scale filled a deep groove on the metal substrate, which was assumed to be formed by the plow of ceramics in the running-in period because of the significant difference in hot hardness between the ceramics and ST. EDX analysis shows that a substantially thinner $\mathrm{O}-\mathrm{Cr}-\mathrm{Si}$ protective layer than that of $\mathrm{Si}_{3} \mathrm{~N}_{4} / \mathrm{ST}$ formed at the scale/substrate interface, indicating that the $\mathrm{SiC}$ ball had broken this protective layer at the initial stage, thereby promoting the further oxidation of the substrate during rubbing. Consequently, it can provide adequate oxide debris to form a thick tribo-oxide layer. Furthermore, a thin layer of silica transferred from the counterface ( $\mathrm{SiC}$ ball) was observed at the top of Fig. 11(c). This material transfer can reduce the surface chemical reactivity of ST owing to the inertness of silica.

\section{Discussion}

\subsection{Wear mechanism of ball/MS tribo-pairs}

Tribology at high temperatures is a complex process that involves many influencing factors such as thermo-softening, oxidation, microstructure change, and thermal fatigue, in which surface oxidation is critical in determining friction and wear. The roles of the oxide scale and mating surface on tribology were investigated in this study by comparing the tribological behavior of MS and ST. For the MS surface at $900{ }^{\circ} \mathrm{C}$, a thick oxide layer measuring approximately $88 \mu \mathrm{m}$ was formed during heating. Because the HSS was located above the disc during heating, its temperature was lower, i.e., approximately $680^{\circ} \mathrm{C}$, as measured in Ref. [3]; hence, its oxidation was minimized. When the ball was about to establish contact with the disc surface, severe adhesive wear was the dominant wear mechanism in the running-in period, resulting in the coverage of clean HSS scar by the transfer of oxide scale from the MS. The oxide-oxide contact reduced the friction slightly; however, with the growth of this scale layer, scale spalling, surface roughening, and fluctuating friction will occur during the running-in period. During the steady-state period, an adherent, compact, and non-spallation glaze layer was developed on the HSS scar, as shown in Fig. 4(a), in which the HSS exhibited abrasive wear because of the corresponding hard glaze layer formed on the disc surface. The use of the ceramic as the upper sliding part stabilized the sliding process. The ceramics experienced mild abrasive wear and exhibited a smooth and compact worn scar morphology. The disc scars with the glaze layer were extremely smooth and compact, and the scale was removed uniformly. Hence, the MS was primarily degraded through mild oxidational wear.

\subsection{Wear mechanisms of ball/ST tribo-pairs}

\subsubsection{Difference in deformation layer depth}

For MS, the calculation formula indicates that the testing temperature of $900{ }^{\circ} \mathrm{C}$ is above the austenite temperature $\left(\mathrm{A}_{3}\right)$ and recrystallization temperature (typically 0.4-0.5 times the melting temperature). Consequently, dynamic recovery and recrystallization occurred, in which strain-free grains were formed [28]. Furthermore, furnace cooling from $900{ }^{\circ} \mathrm{C}$ implied a full annealing process involving static recovery, static recrystallization, and grain growth [29]. These two factors can cause the deformed grains to recrystallize completely. Hence, no deformed layers were observed.

The low to medium stacking default energy of 
253 MA austenitic STs limits their dynamic recovery, and only a critical deformation can induce dynamic recrystallization [30]; such a deformation is relatively small in the tribological test. Figure 9 shows that all three test ball materials can deform the ST significantly to produce a deep plastic deformed layer, and that the depths of the deformation layers on the ST wear surfaces differed significantly depending on the type of mating surface. The ST against $\mathrm{Si}_{3} \mathrm{~N}_{4}$ had the deepest deformed layers, followed by those against $\mathrm{SiC}$ and HSS. This phenomenon was caused primarily by the actual forces exerted on real contact points, where the deformation layer thickness and size of wear debris tended to increase with those forces [31]. Although the same nominal loads were applied, different pressures were applied. Because the ceramics can retain a higher elastic modulus than HSSs at high temperatures [32], they can generate higher Hertz contact stresses.

\subsubsection{Summary of wear mechanisms}

When rubbing against the ST, an oxide scale could not form on the surface owing to the strong oxidation resistance, as shown in Fig. 2. Furthermore, the yield and ultimate strength of the ST declined significantly at $900{ }^{\circ} \mathrm{C}$, as shown in Table 2 . When the ST was about to establish contact with the upper HSS, the high contact stress caused repetitive and accumulative plastic deformation, work hardening, and tribooxidation in the ductile ST. The tribo-oxidation resulted in the formation of a thin $0.3 \mu \mathrm{m}$ glaze layer
(Fig. 11(a)), which rendered the hardness measurement slightly difficult. Figures 8 and 10 show that the thicknesses of the glaze layers differed owing to the tribo-pair differences, but their mechanical properties were similar. Therefore, it can be postulated that the hardness of the thin glaze layer was similar to that of the thick layers, i.e., approximately $21 \mathrm{GPa}$. Such a thin glaze layer cannot prevent a direct contact between the HSS asperities and the ST substrate. As reported in Ref. [33], the thickness of the oxide layer should exceed $3 \mu \mathrm{m}$ to prevent material transfer. The HSS has a relatively high chemical reactivity and dissolution rate with steels; therefore, the fractures were generated inside the ST due to low shear strength, and material transfer occurred from ST to the HSS surface (Fig. 12), thereby resulting in a low friction coefficient because of the low interfacial shear strength (Fig. 3(d)). This is the main reason that caused the sticking problem in the hot forming of ST, i.e., the direct contact between the metal base and tool surface [33, 34]. The ST adhering to the HSS ball underwent significant plastic deformation, and plastic flow occurred toward the edge of the contact zone owing to the pressure gradient in the contact zone (Fig. 12) [19]. Finally, the ST on the HSS surface was extruded from the contact zone, resulting in the loss of ST. This wear process, including material transfer, plastic flow toward the edge, and extrusion from the contact zone, resulted in the continuous removal of ST during the sliding process; consequently, the deepest wear track and the maximum wear rate of ST were obtained, as shown
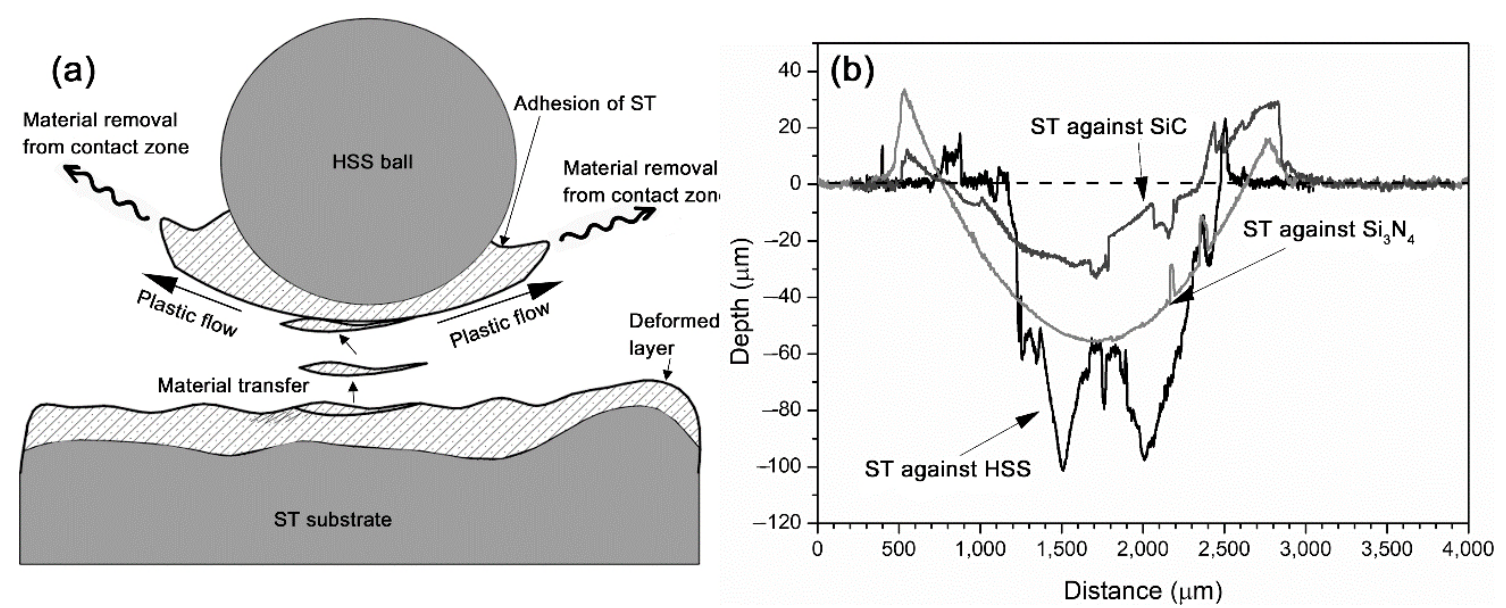

Fig. 12 (a) Schematic diagram of wear mechanism of ST against HSS, where sliding direction is perpendicular to the paper; (b) profile lines of wear tracks on ST against different balls. 


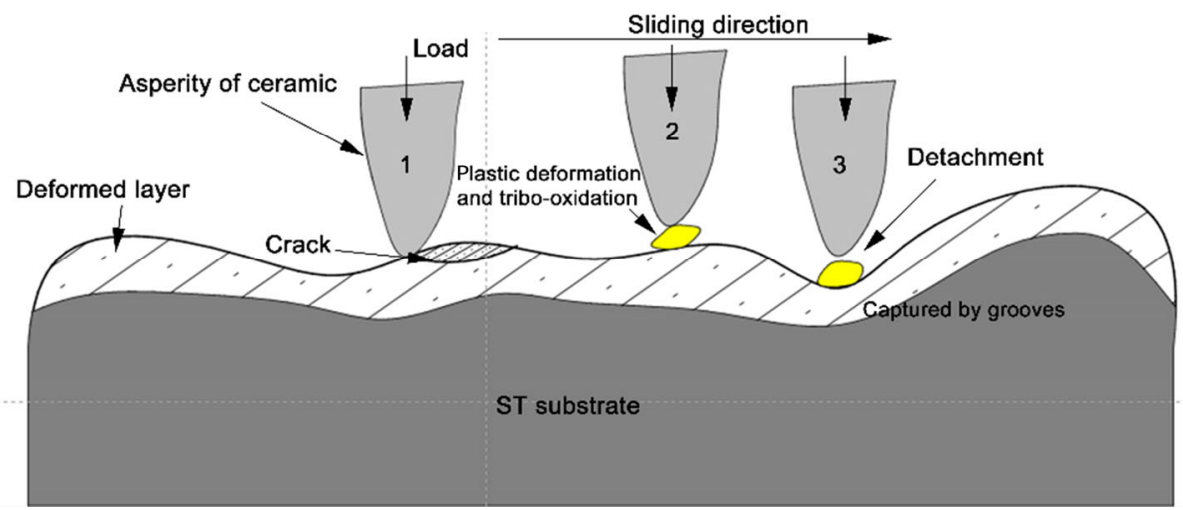

Fig. 13 Schematic diagram of wear mechanism and formation of anti-wear tribo-oxidation layer.

in Figs. 7(b) and Fig. 12(b). Because of this wear mechanism, the tribo-oxide layer could not be established on the ST worn surface when it was sliding against the HSS.

Ceramics exhibit high mechanical strength and poor chemical reactivity with steel. They can deform ST more significantly to produce a deeper and more hardened deformed layer than HSS, as shown in Fig. 9. The hot hardness of the ceramics enabled the ceramic asperities to micro-cut the soft STs at the initial contact, as presented by stage 1 in Fig. 13, resulting in the formation of many deep grooves (Fig. 9). The formed wear debris did not indicate material transfer and adhesion owing to the inert chemical reactivity of the ceramics. They circulated at the interface and underwent repetitive plastic deformation, work hardening, fracture, and tribo-oxidation, as shown in stage 2 of Fig. 13. The oxidized debris were entrapped by the grooves plowed by the hard ceramic asperities in the subsequent sliding process (stage 3 ). Because a significant amount of wear debris was circulating at the interface, this oxidized debris will agglomerate and become compacted/sintered under a high temperature and the applied load. When these tribo-oxide layers are formed and begin to develop further, the debris can be captured more easily by the obstacles on these tribo-oxide layers [2]. The development of such a tribo-oxide layer is widely acknowledged to be the solution to severe adhesive wear between contact sliding metals at elevated temperatures [17, 31, 32].

The mating surfaces, $\mathrm{SiC}$ and $\mathrm{Si}_{3} \mathrm{~N}_{4}$, exerted different effects on the thickness of the tribo-oxide glaze layer, as shown in Fig. 9. This is primarily due to the differences in their mechanical properties. $\mathrm{SiC}$ has a higher hardness (34.9 GPa) and Young's modulus (304.7 GPa) than $\mathrm{Si}_{3} \mathrm{~N}_{4}$, as listed in Table 1. This enables $\mathrm{SiC}$ to penetrate more deeply into ST and generate deeper grooves and more wear debris; consequently, a tribo-oxide layer thicker than the $\mathrm{Si}_{3} \mathrm{~N}_{4}$ counterface is formed, as shown in Fig. 10. It was reported that strong adhesion wear and severe material transfer of ST onto the rubbing ceramic surface occurred because of the high chemical affinity when the tribological test was performed at room temperature [35]. Hence, it can be inferred that temperature significantly affects the interaction between $\mathrm{Si}_{3} \mathrm{~N}_{4}$ and iron, thereby affecting the formation of inert silica on the surface of $\mathrm{Si}_{3} \mathrm{~N}_{4}$.

\subsubsection{Contribution of different layers to wear resistance}

Regarding the worn surface on the ST against ceramics, two layers (glaze layer and work-hardened layer) shielded the substrate. The mechanical properties in Fig. 10(b) show that the glaze layer had a hardness of $21 \mathrm{GPa}$, which was slightly higher than that of $\mathrm{Si}_{3} \mathrm{~N}_{4}$ and significantly lower than that of SiC. The workhardened layer below the glaze layer provided support for the hard and brittle glaze layer. Therefore, the severe abrasion of the ST by $\mathrm{Si}_{3} \mathrm{~N}_{4}$ can be reduced significantly, and mild oxidational wear can be achieved. Consequently, a low wear rate and a stable friction coefficient were generated in the stable sliding stage for the $\mathrm{ST} / \mathrm{Si}_{3} \mathrm{~N}_{4}$ tribo-pair.

For the SiC/ST tribo-pair, the soft ST was severely plowed by the superior hard $\mathrm{SiC}$, thereby resulting in a large amount of wear debris and a thick glaze layer. The glaze layer can significantly reduce the penetration depth of $\mathrm{SiC}$ asperities owing to the substantial improvement in hardness and Young's modulus. 
However, $\mathrm{SiC}$ can still plow the glaze layer owing to the significant hardness difference, and these glaze layers will exhibit microfractures owing to their brittleness and transition into fine debris. Some of the fine debris were removed from the contact zone, thereby resulting in mild oxidational wear. Meanwhile, the remainder retained on the wear track and were recycled to provide a debris source for the formation of the glaze layer. The ceramics indicated low wear rates and acceptable friction; additionally, they promoted the formation of thick tribo-oxide layers on the ST surface. However, both the $\mathrm{Si}_{3} \mathrm{~N}_{4}$ and $\mathrm{SiC}$ balls presented drawbacks of severe pull-out and fracture wear under extreme pressures. Therefore, these drawbacks should be addressed such that $\mathrm{Si}_{3} \mathrm{~N}_{4}$ and $\mathrm{SiC}$ ceramics can perform well against high-chromium STs.

\section{Conclusions}

In this study, the tribological behavior of different tool counterfaces against MS and high-chromium ST were investigated, in which commercial high-speed steel, $\mathrm{Si}_{3} \mathrm{~N}_{4}$, and $\mathrm{SiC}$ were tested. Their wear mechanisms against MS and ST were investigated, and several conclusions were obtained.

1) The ceramics presented better wear resistance against MS than HSS, where $\mathrm{Si}_{3} \mathrm{~N}_{4}$ exhibited the lowest friction coefficient and wear rate. The HSS exhibited severe abrasive wear owing to thermal softening and destroyed the glaze layer on the MS under the tribological conditions tested, thereby increasing the wear of the MS.

2) When rubbing against high-chromium ST, the HSS presented sticking problems, and both $\mathrm{SiC}$ and $\mathrm{Si}_{3} \mathrm{~N}_{4}$ exhibited severe pull-out wear owing to their low toughness. However, the use of ceramics can promote the establishment of a thick tribo-oxide layer $(>3 \mu \mathrm{m})$ on ST surfaces, thereby reducing the wear of ST and its transfer to the counterface. Furthermore, a thicker glaze layer will decrease the amount of wear.

3) The use of ceramics enabled deep grooves to be plowed on a clean ST surface during initial contact, thereby promoting the establishment of a glaze layer by improving the entrapment of wear debris. Consequently, friction, wear, and sticking problems were reduced. The obtained results suggest that ceramics are a promising material for deforming ST at high temperatures.

\section{Acknowledgements}

This work is financially supported by the Young Scientists Fund of the National Natural Science Foundation of China (Grant No. 51905213), the Natural Science Foundation of Guangdong (906055014066), and the Fundamental Research Funds for the Central Universities (No. 21619337).

Open Access This article is licensed under a Creative Commons Attribution 4.0 International License, which permits use, sharing, adaptation, distribution and reproduction in any medium or format, as long as you give appropriate credit to the original author(s) and the source, provide a link to the Creative Commons licence, and indicate if changes were made.

The images or other third party material in this article are included in the article's Creative Commons licence, unless indicated otherwise in a credit line to the material. If material is not included in the article's Creative Commons licence and your intended use is not permitted by statutory regulation or exceeds the permitted use, you will need to obtain permission directly from the copyright holder.

To view a copy of this licence, visit http://creativecommons.org/licenses/by/4.0/.

\section{References}

[1] Blau P J. Elevated-temperature tribology of metallic materials. Tribol Int 43(7): 1203-1208 (2010)

[2] Hardell J, Hernandez S, Mozgovoy S, Pelcastre L, Courbon C, Prakash B. Effect of oxide layers and near surface transformations on friction and wear during tool steel and boron steel interaction at high temperatures. Wear 330-331: 223-229 (2015)

[3] Zhu H T, Zhu Q, Tieu A K, Kosasih B, Kong C. A simulation of wear behaviour of high-speed steel hot rolls by means of high temperature pin-on-disc tests. Wear 302(1-2): 1310-1318 (2013)

[4] Stott F H, Jordan M P. The effects of load and substrate hardness on the development and maintenance of wearprotective layers during sliding at elevated temperatures. Wear 250(1-12): 391-400 (2001) 
[5] Roy M, Pauschitz A, Wernisch J, Franek F. Effect of mating surface on the high temperature wear of 253 MA alloy. Mater Corros 55(4): 259-273 (2004)

[6] Cheng X W, Jiang Z Y, Wei D B, Wu H, Jiang L Z. Adhesion, friction and wear analysis of a chromium oxide scale on a ferritic stainless steel. Wear 426-427: 1212-1221 (2019)

[7] Cheng X W, Jiang Z Y, Kosasih B, Wu H, Luo S Z, Jiang $\mathrm{L} Z$. Influence of Cr-rich oxide scale on sliding wear mechanism of ferritic stainless steel at high temperature. Tribol Lett 63(2): 1-13 (2016)

[8] Aruna M., Dhanalakshmi V., Mohan S. Wear analysis of ceramic cutting tools in finish turning of Inconel 718. Int $J$ Eng Sci Technol 2(9): 4253-4262 (2010)

[9] Wang B, Liu Z Q. Cutting performance of solid ceramic end milling tools in machining hardened AISI H13 steel. Int $J$ Refract Met Hard Mater 55: 24-32 (2016)

[10] Davis J R. ASM Specialty Handbook: Tool Materials. Geauga (USA): ASM International, 1995.

[11] Lengauer M, Danzer R. Silicon nitride tools for the hot rolling of high-alloyed steel and superalloy wires-Crack growth and lifetime prediction. J Eur Ceram Soc 28(11): 2289-2298 (2008)

[12] Jack D H. Ceramic cutting tool materials. Mater Des 7(5): 267-273 (1986)

[13] Wan S H, Tran B H, Tieu A K, Xia Y N, Zhu H T, Cui S G, Zhu $\mathrm{Q}$. The influence of water addition on high-temperature tribological properties of interstitial free steel sliding against different counterparts. Tribol Trans 61(4): 713-725 (2018)

[14] Information. http://www.atlassteels.com.au/documents/ Atlas\%20Grade\%20datasheet\%20253MA\%20rev\%20May\% 202008.pdf, 2008.

[15] Hougardy H P. Werkstoffkunde Stahl Band 1: Grundlagen. (in German). Düsseldorf (Gemmany): Springer/Verlag Stahleisen, 1984.

[16] Chen J, Xiong Y G, Zhou Y Q, Xue W, Jin W L. Deterioration of mechanical properties of novel constructional steel material at elevated temperatures. Procedia Eng 27: 1602-1608 (2012)

[17] Chen J, Young B, Brian U. Behavior of high strength structural steel at elevated temperatures. J Struct Eng 132(12): 1948-1954 (2006)

[18] Suárez S, Ramos-Moore E, Mücklich F. A high temperature X-ray diffraction study of the influence of MWCNTs on the thermal expansion of MWCNT/Ni composites. Carbon 51: 404-409 (2013)

[19] Stachowiak G W, Batchelor A W. Engineering Tribology. Oxford (UK): Butterworth-Heinemann, 2006.

[20] Cho S J, Um C D, Kim S S. Wear and wear transition in silicon carbide ceramics during sliding. J Am Ceram Soc 79(5): 1247-1251 (1996)

[21] Lankford J. Comparative study of the temperature dependence of hardness and compressive strength in ceramics. J Mater Sci 18(6): 1666-1674 (1983)

[22] Utsunomiya H, Doi S, Hara K I, Sakai T, Yanagi S. Deformation of oxide scale on steel surface during hot rolling. CIRP Ann 58(1): 271-274 (2009)

[23] Dutta S. Fracture toughness and reliability in hightemperature structural ceramics and composites: Prospects and challenges for the 21st century. Bull Mater Sci 24(2): 117-120 (2001)

[24] Suh N P. An overview of the delamination theory of wear. Wear 44(1): 1-16 (1977)

[25] Cao Y, Zhang C H, Zhang C, Wen Y, Li Q, Wang D L, Huang G J, Liu Q. Effect of dynamic strain aging and precipitation on the hot deformation behavior of $253 \mathrm{MA}$ heat-resistant alloy. J Mater Sci 54(2): 1716-1727 (2019)

[26] Archard J, Hirst W. The wear of metals under unlubricated conditions. Proc R Soc Lond A 236: 397-410 (1956)

[27] Smeltzer W W. The breakdown of the protective oxide film on transition metal alloys. Acta Met 8: 268-270 (1960)

[28] Huang K, Logé R E. A review of dynamic recrystallization phenomena in metallic materials. Mater Des 111: 548-574 (2016)

[29] Hu G X, Cai X, Rong Y H. Fundamentals of Materials Science. (in Chinese). Shanghai (China): Shanghai Jiao Tong University Press, 2000

[30] Humphreys F J, Hatherly M. Recrystallization and Related Annealing Phenomena. 2nd edn. Oxford (UK): Elsevier Science, 2004.

[31] Soda N, Kimura Y, Tanaka A. Wear of some F.C.C. metals during unlubricated sliding Part III: A mechanical aspect of wear. Wear 40(1): 23-35 (1976)

[32] Meléndez-Martínez J J, Jiménez-Melendo M, DomínguezRodríguez A, Wötting G. High temperature mechanical behavior of silicon nitride ceramics. Mater Sci Forum 383: 13-18 (2001)

[33] Jin W, Choi J Y, Lee Y Y. Nucleation and growth process of sticking particles in ferritic stainless steel. ISIJ Int 40(8): 789-793 (2000)

[34] Dubois A, Luc E, Dubar M, Dubar L, Thibaut C, Damasse J M. Initiation of sticking during hot rolling of stainless steel plate. Procedia Eng 81: 1958-1963 (2014)

[35] Zhao X Z, Liu J J, Zhu B L, Miao H Z, Luo Z B. Friction and wear of $\mathrm{Si}_{3} \mathrm{~N}_{4}$ ceramic/stainless steel sliding contacts in dry and lubricated conditions. J Mater Eng Perform 6(2): 203-208 (1997) 


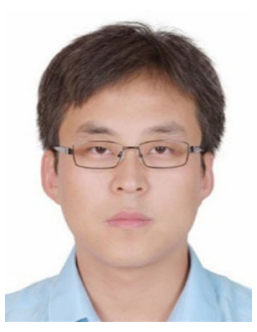

Shaogang CUI. He received his B.S. and M.S. degrees from Northeastern University, China, and his Ph.D. degree from University of Wollongong, Australia, in 2018. He once worked in the Institute of Research

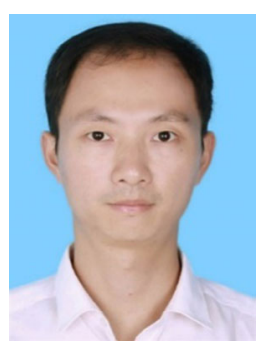

Yangzhen LIU. He received his M.S., and Ph.D. degrees from Kunming University of Science and Technology in 2014, and Xi'an Jiaotong University in 2018, respectively. He joined the Institute of Advance Wear \&

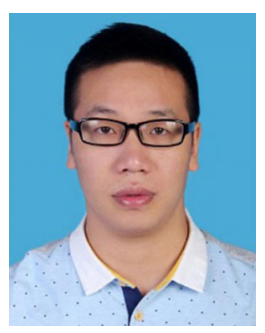

Long WANG. He received his M.S. degree in 2017 from the Lanzhou Institute of Chemical Physics, Chinese Academy of Sciences. Then from 2018 to 2021, he pursues of Iron and Steel, Sha-steel as a research assistant, and now worked as a lecturer in the Institute of Advance Wear \& Corrosion Resistant and Functional Materials in Jinan University. His research field includes the tribology in hot metal forming and wear-resistant castings.

Corrosion Resistant and Functional Materials in Jinan University as a lecturer in 2018. He has published more than 20 peer-reviewed papers that received more than 400 citations and has the h-index of 11 . His research interests cover the friction and wear of metal materials and current carrying friction.

his Ph.D. degree from University of Wollongong, Australia. His research interest is high-temperature tribology and lubrication, self-lubricating materials, and tribology for metal forming process. 